\title{
Predicting development, metabolism and secondary production for the invertebrate predator Bythotrephes
}

\author{
JOHN T. LEHMAN, * DONNA MARIE BILKOVIC† AND CHRIS SULLIVAN* \\ ${ }^{*}$ Department of Biology and Centre for Great Lakes and Aquatic Sciences, Natural Science Building, University of Michigan, \\ Ann Arbor, MI 48109, U.S.A. \\ +Virginia Institute of Marine Science, College of William and Mary, Gloucester Point, VA, U.S.A.
}

\section{S U M M A R Y}

1. Rates of embryonic and post-embryonic development for Bythotrephes cederstroemi from Lakes Erie, Huron and Michigan are represented almost equally well by three empirical models across water temperatures ranging from about $12-22^{\circ} \mathrm{C}$, but at lower temperatures two of the competing models fail and an exponential development rate model proves most robust.

2. Clutch masses of parthenogenic females can greatly exceed the tissue mass of the mother. Clutch size is strongly correlated with the mass of reproductive adults, accounting for over $90 \%$ of the variation among individuals. Hence, the mass gain from neonate to reproductive adult can be estimated directly from clutch size.

3. Tissue stoichiometries, respiration quotients and stoichiometries of $\mathrm{C}$ and $\mathrm{N}$ metabolism were determined experimentally, extending the predictions of existing respiration and growth models.

4. A predictive model for growth and production by the invertebrate predator has advantages over previous model formulations owing to our expanded calibration data base. The model is presented in a modular design that is easily upgraded as additional calibration data become available.

\section{Introduction}

The successful invasion of North America by Bythotrephes (Crustacea: Cladocera) has prompted keen interest in its biology, natural history and ecological interactions (Cullis \& Johnson, 1988; Garton, Berg \& Fletcher, 1990; Sprules, Riessen \& Jin, 1990; Bur \& Klarer, 1991; Lehman, 1987, 1988, 1991; Vanderploeg, Liebig \& Omair, 1993; Berg \& Garton, 1988, 1994). Recent communications by Lehman \& Branstrator (1996) and Lehman \& Lehman (1996) call attention to the need for presentation of additional data about rates of embryonic and post-embryonic development for the organism, as well as about many other aspects of its biology. One of the problems that has confronted investigators is the choice of an appropriate growth model from which secondary production may be calculated. Previously, models have been developed and calibrated against data from Lake Michigan animals, but it was not known how generally the

results could be applied. The generality of model results is important because the organism is now expanding its range into small lakes in the Great Lakes region (Yan \& Pawson, 1997).

Past works reported on the P economy and ingestion efficiency (Burkhardt \& Lehman, 1994), respiration (Lehman \& Branstrator, 1995), C and P assimilation (Lehman, 1993), size variation (Lehman \& Lehman, 1996), and lipid contents (Bilkovic \& Lehman, 1997) of animals from Lake Michigan, Lake Huron and Lake Erie. The purpose of this paper is severalfold. (i) We provide data about rates of metabolism and of embryonic and post-embryonic development for Bythotrephes that increase the power and generality of previous estimates, and which improve predictive models. (ii) We present information about the $\mathrm{N}$ economy of the organism to augment existing information about its $\mathrm{C}$ and $\mathrm{P}$ metabolism, and to sharpen 


\section{J.T. Lehman, D.M. Bilkovic and C. Sullivan}

predictions about its tissue stoichiometry and that of its prey. (iii) We demonstrate the relationship between weight gain during maturation and clutch size variability. Finally, (iv) we present a specific algorithm for secondary production estimates which can accomodate field data and additional experimental results.

Because this predator exhibits phenotypic plasticity in many of its demographic and natural history traits, much of the original data is presented in explicit tabular form so that the numbers can be compared to similar properties of populations in other lakes.

\section{Methods}

Sample collections and experimental methods followed protocols of Lehman \& Branstrator (1995). During 1993, 1995 and 1996 experiments were conducted with animals from Lakes Erie, Huron and Michigan in order to integrate geographical and genetic idiosyncrasies that might otherwise restrict model applications. Animals were incubated in darkness during shipboard experiments at temperatures within $2{ }^{\circ} \mathrm{C}$ of collection temperature.

The status of existing data collections were also reviewed. Based on assertions that the temperatures reported by Yurista (1992) in development rate experiments were measured values (editor's note in Lehman \& Branstrator, 1996; p. 933), the stripchart recordings of temperatures from shipboard instruments operated by one of us (J.T.L.) on the R/V Laurentian during 1990 were examined. Control subprograms written by J.T.L. were installed on a Hewlett-Packard HP71 computer interfaced with an HP3421 acquisition/ controller for the shipboard incubators. The computer algorithms converted thermistor resistances to temperatures, and also operated two solid state AC relays that apply 110 VAC power to conventional small refrigerators. The compressors receive electrical power (in these experiments for 2 min minimum) and cause temperatures to drop quickly each time the experimental temperatures exceed the set points. After rapid chilling by approximately one degree, temperatures rise slowly by conduction. Set points for the temperatures in the incubators were $16^{\circ} \mathrm{C}$ and $20^{\circ} \mathrm{C}$ (Yurista, 1992; p. 1120 and table 2). As reported by Lehman \& Branstrator (1996), measured mean temperatures with this apparatus are usually less than the set point temperatures. In order to provide a reproducible data set, we have tried to use the measured temperatures from the instruments, rather than set point temperatures; for instance, the data at measured $\mathrm{T}=19^{\circ} \mathrm{C}$ reported by Burkhardt \& Lehman (1994) from 31 July $1990 \mathrm{had}$ a set point of $20^{\circ} \mathrm{C}$. It was not possible to calculate the temperatures at the development rates reported by Yurista (1992) for set points of 16 and $20^{\circ} \mathrm{C}$ because the experiment dates were not reported. The potential importance of errors in the assigned temperature for a development experiment were thus assessed with reference to magnitudes of uncertainty in measurement of the development rates themselves.

If $T$ is development temperature, $f(T)$ is development rate, and $\mathrm{CV}$ is the typical coefficient of variation (SD/ mean) for development rate at constant temperature, then the individual components contributing uncertainty to estimates of a development rate vs. temperature function are $[\mathrm{CV} \times \mathrm{f}(T)]$ and $[\mathrm{df}(T) / \mathrm{d} T \times \delta T]$, where $\delta T$ is the temperature deviation. The magnitudes of these two components were evaluated from empirical data.

Changes in tissue stoichiometry of unfed animals were measured using broods of clonal sibling neonates. Adult females with parthenogenic embryos in the black-eye stage were isolated in filtered lake water until parturition. Then each clutch of $n$ siblings was divided in half, with the largest integer number of neonates represented by the formula $(n / 2)$ immediately frozen on Teflon disks over Dry Ice for subsequent analysis. The remaining neonates from each clutch were incubated individually in filtered lake water (GF/C) for intervals from 4 to $28 \mathrm{~h}$. The incubation intervals were based on expectations of the minimum intervals for which changes might be measurable, based on pilot experiments conducted in 1993. Animals were then frozen, returned to Ann Arbor, and freeze-dried at $-55^{\circ} \mathrm{C}$ for $6 \mathrm{~h}$ minimum. Freeze-dried animals were stored over anhydrous $\mathrm{CaSO}_{4}$ in a vacuum desiccator pending further analysis. Analyses included dry weight (Cahn Model 29 electrobalance at $1 \mu \mathrm{g}$ resolution), carbon, hydrogen, nitrogen $(\mathrm{CHN})$ content, and total lipid content (Bilkovic \& Lehman, 1997).

\section{Results}

\section{Development models}

Original data for embryo development (onset of eyepigment to neonate release) and durations of post- 
Table 1 Duration of embryo development $\left(D_{\mathrm{e}}, \mathrm{h}\right)$ and postembryonic instar duration during shipboard incubations with animals from different Great Lakes. $n$ is number of observations; $\mathrm{SD}$ is standard deviation (original data)

\begin{tabular}{llllrrr}
\hline Stage & Lake & Date & $T\left({ }^{\circ} \mathrm{C}\right)$ & $D_{\mathrm{i}}(\mathrm{h})$ & $\mathrm{SD}$ & $n$ \\
\hline$D_{\mathrm{e}}$ & Erie & Aug. '95 & 15.5 & 52.3 & 6.9 & 9 \\
$D_{\mathrm{e}}$ & Erie & Aug. '95 & 19.4 & 36.3 & 3.4 & 8 \\
$D_{\mathrm{e}}$ & Huron & Aug. '96 & 17.2 & 49.7 & 5.3 & 15 \\
$D_{\mathrm{e}}$ & Huron & Aug. '96 & 19.1 & 33.6 & 4.0 & 7 \\
$D_{\mathrm{e}}$ & Huron & Aug. '95 & 21.1 & 29.5 & 4.0 & 15 \\
$D_{\mathrm{e}}$ & Mich & July '93 & 15.3 & 48.2 & 5.5 & 4 \\
$D_{\mathrm{e}}$ & Mich & Aug. '96 & 19.1 & 37.1 & 2.8 & 3 \\
$D_{\mathrm{e}}$ & Mich & Aug. '96 & 19.1 & 36.9 & 3.9 & 10 \\
$D_{\mathrm{e}}$ & Mich & July'93 & 21.1 & 29.2 & 3.0 & 10 \\
$D_{1}$ & Mich & Aug. '96 & 19.1 & 89.5 & 18.4 & 35 \\
$D_{2}$ & Mich & Aug. '96 & 17.2 & 113.7 & 7.7 & 5 \\
$D_{2}$ & Mich & Aug. '96 & 19.1 & 88.5 & 20.2 & 15 \\
$D_{3}$ & Mich & Aug. '96 & 19.1 & 96.0 & 22.1 & 10 \\
$D_{3}$ & Huron & Aug. '96 & 19.1 & 106.4 & 20.9 & 5 \\
\hline
\end{tabular}

embryonic instars are reported in Table 1. These data expand table 2 of Lehman \& Branstrator (1995), nearly doubling its information. Weighted least-squares linear regressions (SYSTAT 5.03, procedure MGLH) using the number of broods that completed the specified development period as the weighting factor reveal that the full data set is fitted almost equally by the three simple models (Fig. 1) which were described by Lehman \& Branstrator (1996). As explained by Lehman \& Branstrator (1996), the three models represent common formulations for development rate data. Model 1 is a simplified, first-order linear approximation to model 3, and model 2 is a double-logarithm transformation broadly applied to curvilinear relations. Linear regression of model 1 ,

$1 D_{\mathrm{e}}=a T+b$

produced $a=0.00204(\mathrm{SE}=0.00003)$ and $b=-0.01151$ $(\mathrm{SE}=0.00046) ; r^{2}=0.96$. Stepwise linear regression of model 2

$\ln \left(D_{\mathrm{e}}\right)=a+b \ln (T)+c \ln (T)^{2}$

rejected the term $\ln (T)^{2}$; the appropriate form for model 2 is consequently

$\ln \left(D_{\mathrm{e}}\right)=a+b \ln (T)$

where $a=8.27(\mathrm{SE}=0.05), b=-1.581 \quad(\mathrm{SE}=0.017)$, residual mean square error $=0.004$, and $r^{2}=0.97$. With model 3,

$\ln \left(1 / D_{\mathrm{e}}\right)=a T+b$
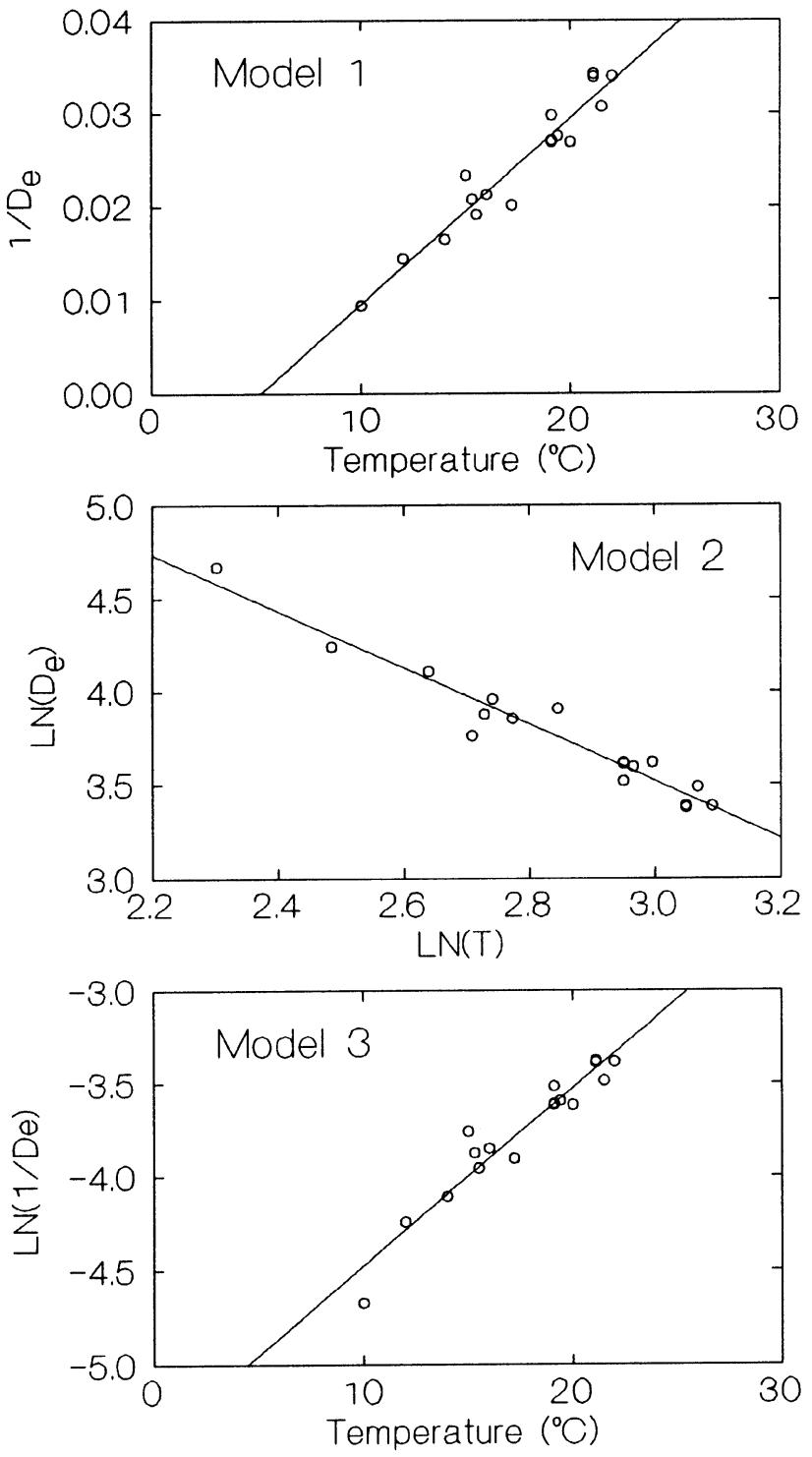

Fig. 1 Three alternative models for estimation of the duration of embryo development $\left(D_{e}, h\right)$ from water temperature. Empirical data are from Lehman \& Branstrator (1995, table 2, eight data points) and from Table 1 (nine original data points).

$a=0.101 \quad(\mathrm{SE}=0.001), b=-5.547 \quad(\mathrm{SE}=0.023)$, and $r^{2}=0.96$.

The F-ratios for these three models differ by less than a factor of 2, the residuals are acceptable, and no model could be rejected during calibration. Within the span of the calibration data, each empirical model could be used interchangeably. Between 10 and $22^{\circ} \mathrm{C}$, the maximum difference among predictions of $D_{\mathrm{e}}$ averages only $6 \%$ of the mean predictions made by the three models, which is less than measurement error (Table 1). At lower temperatures, however, the 
three models diverge, and only model 3 appears to retain its predictive strength as the data range is expanded to low temperatures. Preliminary tests in July and August 1993 indicated that development proceeds slowly at typical refrigerator temperatures, so during August 1996 we incubated five parthenogenic clutches with Lake Erie females at $3{ }^{\circ} \mathrm{C}$. All five females were introduced to experimental conditions at the first appearance of pink eye pigment, and all five progressed through the red-eye stage of embryo development and the black-eye stage. Time marking continued until the clutches progressed to fully developed embryos. One of the clutches hatched successfully after $D_{\mathrm{e}}=218 \mathrm{~h}$, which is predicted well by extrapolation of model 3 (190 h), but not by model 1 (impossible) or model 2 (690 h). The four other experimental clutches all reached full development at $3{ }^{\circ} \mathrm{C}$ but the sluggish neonates at that temperature could not rupture the brood sac and they all died at c. 200 h. Dissected specimens had the appearance of typical neonates at birth, with appendages and setae seemingly well developed. Failure occurred in achieving parturition, rather than in embryonic development, per se. Developmental progression from red-eye to black-eye embryo stages demonstrates that development can proceed at the low temperature, thus contradicting predictions of model 1. Apparent full development of embryos at 200 rather than $700 \mathrm{~h}$ seems to contradict model 2. Consequently, model 3 was selected for further work.

With model 3, the formulation for development rate, $\mathrm{f}(T)$, is:

$\mathrm{f}(T)=\exp (a T+b)$

and $\mathrm{df}(T) / d T=a \times \mathrm{f}(T)$, where $a=0.101$. For the data plotted in Fig. 1, the average CV for embryo development time $\left(D_{\mathrm{e}}\right)$ is $0.133, \mathrm{SE}=0.010, n=17$. Thus, by first-order error analysis, the magnitudes of $\mathrm{CV} \times \mathrm{f}(T)$ and $\mathrm{df}(T) / d T \times \delta T$ are similar for temperature deviations $(\delta T)$ of about $0.75{ }^{\circ} \mathrm{C}$. This result demonstrates that reported experimental temperatures must be recorded to within a few tenths of a degree in order to guarantee that temperature variations do not dominate the variance in development rate measurements for this organism.

For post-embryonic development, we applied linear scaling of instar durations to embryo duration (Lehman \& Branstrator, 1995):
Table 2 Parameter estimates for embryonic and postembryonic development rates of Bythotrephes, using model 3 $\left[\ln \left(1 / D_{\mathrm{e}}\right)=a T+b\right]$.

\begin{tabular}{lcl}
\hline Model parameter & Mean estimate & SE \\
\hline$a$ & 0.101 & 0.001 \\
$b$ & -5.547 & 0.023 \\
$F_{1}$ & 2.140 & 0.201 \\
$F_{2}$ & 1.987 & 0.287 \\
$F_{3}$ & 2.578 & 0.644 \\
\hline
\end{tabular}

$D_{1}=F_{1} \times D_{\mathrm{e}}$

$D_{2}=F_{2} \times D_{\mathrm{e}}$

$D_{3}=F_{3} \times D_{\mathrm{e}}$

where $F_{\mathrm{i}}$ is the instar-specific scaling factor, $D_{\mathrm{i}}$ is the instar-specific development time, and $D_{\mathrm{e}}$ is predicted by model 3. The parameters were estimated by weighted non-linear regression, Simplex method (SYSTAT 5.03), using the number of broods that completed the development period as the weighting factor at each temperature (Table 2). The reported $D_{3}$ at $12.7^{\circ} \mathrm{C}$ from Yurista (1992) was included, despite indications that it is anomalous (Lehman \& Branstrator, 1996).

The parameters for model 3 (Table 2) permit formulation of a growth rate, or weight-at-age model (table 2 of Lehman \& Branstrator, 1996), improved from an earlier version by incorporation of a mean age for females carrying embryos in the black-eye stage (3BE). To test for non-linearity in the weight-at-age data, we examined the model

$\ln \left(W_{\text {rel }}\right)=a \times t_{\text {rel }}+b \times t_{\text {rel }}^{2}$

by stepwise linear regression, where $W_{\text {rel }}$ is relative DW (mass of neonate $=1.0$ ), and $t_{\text {rel }}$ is relative age. The stepwise model admitted the linear term $\left(t_{\text {rel }}\right)$, but rejected the second term $\left(t_{\mathrm{rel}}{ }^{2}\right)$ owing to an incremental $F$ of only 1.078 compared with $F=2700$ for the linear term. The accepted one parameter model

$\ln \left(W_{\text {rel }}\right)=a \times t_{\text {rel }}$

with $r^{2}=0.999$ implies that animal dry weight is a simple exponential function of age. We prefer a formulation that uses measurable parameters. Thus, Bythotrephes relative mass at age $t_{\text {rel }}(=t / \Sigma \mathrm{D})$ can be written as

$W_{\text {rel }}=\left(W_{\mathrm{BE}} / W_{0}\right)^{\left(t_{\mathrm{rel}} / 0.95\right)}$ 
Table 3 Masses ( $\mu \mathrm{g} \mathrm{DW}$ ) of adult females at parturition and of their parthenogenic clutches, clutch sizes (E), and neonate averages (Neo) for offshore Lake Erie, 20 June 1995. The ratio Total/Neo is referred to as $W_{\text {rel }}$ in the text

\begin{tabular}{|c|c|c|c|c|c|c|c|}
\hline & Adult & Clutch & $\mathrm{E}$ & Total & Neo & Adult/Neo & Total/Neo \\
\hline & 139.7 & 220.8 & 5 & 360.5 & 44.2 & 3.16 & 8.16 \\
\hline & 102.5 & 198.0 & 5 & 300.5 & 39.6 & 2.59 & 7.59 \\
\hline & 106.7 & 196.4 & 5 & 303.1 & 39.3 & 2.72 & 7.72 \\
\hline & 117.8 & 227.3 & 5 & 345.1 & 45.5 & 2.59 & 7.59 \\
\hline & 138.8 & 303.2 & 6 & 442.0 & 50.5 & 2.75 & 8.75 \\
\hline & 111.0 & 325.3 & 8 & 436.3 & 40.7 & 2.73 & 10.73 \\
\hline & 113.9 & 245.6 & 6 & 359.5 & 40.9 & 2.78 & 8.78 \\
\hline & 137.0 & 202.3 & 5 & 339.3 & 40.5 & 3.39 & 8.39 \\
\hline & 90.2 & 164.5 & 5 & 254.7 & 32.9 & 2.74 & 7.74 \\
\hline & 117.3 & 192.2 & 5 & 309.5 & 38.4 & 3.05 & 8.05 \\
\hline & 91.7 & 102.1 & 3 & 193.8 & 34.0 & 2.69 & 5.69 \\
\hline & 90.6 & 152.2 & 5 & 242.8 & 30.4 & 2.98 & 7.98 \\
\hline & 143.1 & 300.2 & 6 & 443.3 & 50.0 & 2.86 & 8.86 \\
\hline & 118.8 & 232.3 & 5 & 351.1 & 46.5 & 2.56 & 7.56 \\
\hline & 102.3 & 182.5 & 4 & 284.8 & 45.6 & 2.24 & 6.24 \\
\hline & 121.5 & 193.2 & 4 & 314.7 & 48.3 & 2.52 & 6.52 \\
\hline & 129.9 & 312.8 & 6 & 442.7 & 52.1 & 2.49 & 8.49 \\
\hline & 105.3 & 191.6 & 4 & 296.9 & 47.9 & 2.20 & 6.20 \\
\hline & 103.4 & 208.4 & 4 & 311.8 & 52.1 & 1.98 & 5.98 \\
\hline & 138.8 & 267.7 & 5 & 406.5 & 53.5 & 2.59 & 7.59 \\
\hline & 147.7 & 200.7 & 4 & 348.4 & 50.2 & 2.94 & 6.94 \\
\hline & 121.9 & 214.6 & 4 & 336.5 & 53.7 & 2.27 & 6.27 \\
\hline & 106.9 & 230.6 & 6 & 337.5 & 38.4 & 2.78 & 8.78 \\
\hline Mean & 117.2 & 220.2 & 5.0 & 337.4 & 44.1 & 2.68 & 7.68 \\
\hline SD & 17.5 & 53.7 & 1.0 & 65.5 & 6.8 & 0.32 & 1.18 \\
\hline $\mathrm{CV}$ & 0.15 & 0.24 & 0.21 & 0.19 & 0.15 & 0.12 & 0.15 \\
\hline
\end{tabular}

where $W_{0}$ is neonate mass and $W_{\mathrm{BE}}$ is mean mass of $3 \mathrm{BE}$ females. Equivalently, the equation can be expressed as

$W(t)=W_{0} e^{g t}$

where $g=\ln \left(\mathrm{W}_{\mathrm{BE}} / \mathrm{W}_{0}\right) /(0.95 \times \Sigma \mathrm{D})$.

The relative mass gain from neonate to adult varies among lakes and over season (Burkhardt, 1994; Lehman \& Lehman, 1996; Bilkovic \& Lehman, 1997). Equation 11 permits those empirical variations to be incorporated into secondary production models.

\section{Weight accumulation from birth to maturation}

Clutch sizes and weights, as well as the masses of the females that bear them, are shown in Table 3 for animals from Lake Erie in June 1995. Fecund females with black-eye embryos were isolated until parturition. The combined masses of clutch and mother are not different from the masses of seventeen 3BE females in the same collection that were frozen immediately $(P=$ 0.2, one-way ANOVA).

(c) 1997 Blackwell Science Ltd, Freshwater Biology, 38, 343-352
Table 3 reveals the striking fact that the combined mass of the clutch exceeds the mass of the mother in every case, by almost twofold on average. Inspection of the CVs reveals that clutch size and clutch mass are more intrinsically variable than either the mass of the mothers or the mass of individual neonates. It appears that these animals increase their own body mass by less than a factor of three from birth to primiparity. Most of the mass increment goes into the developing clutch. The relative weight gain during life from birth to parturition (final weight of fecund adult female compared to individual neonate mass) ranges by nearly twofold within the population, but it is correlated almost perfectly $(r=0.966)$ with clutch size, $n$. Thus, most of the weight gain experienced by these animals is reproductive tissue, in relatively strict proportion to the numbers of embryos that are produced. Relative weight gain $\left(W_{\mathrm{BE}} / W_{0}\right)$ is consequently predictable from mean clutch size if direct measurements of mass are unavailable.

These high levels of reproductive effort and relatively little post-embryonic growth are consistent with 
Branstrator's (unpublished information) interpretation of life history strategy for Bythotrephes compared with another Cladoceran predator, Leptodora. He points out that Bythotrephes appears to achieve an optimal foraging size by its first or second instar, and that further somatic growth offers no adaptive advantage.

\section{Starvation experiments}

Neonatal animals from Lake Michigan on 17 July 1993 were starved at $15.3^{\circ} \mathrm{C}$, and neonates from Lake Huron on 27 August 1993 were starved at $19^{\circ} \mathrm{C}$ (epilimnion collection temperatures) to test our a priori assumption that lipid would be preferentially depleted. Experimental temperatures were lake water temperatures to avoid temperature acclimation effects. Percent lipid concentrations of the neonates from the two lakes were not significantly different at birth (oneway ANOVA, $P>0.25$ ), which is consistent with findings of Bilkovic \& Lehman (1997) that lipid concentrations are similar across lakes for animals in their first instar. Lipid concentration did decline with starvation (one-tail paired $t$-test, $P<0.002$ ) suggesting that lipid content was differentially depleted. It was discovered that mass changes over starvation periods of only several hours were not large enough to dominate the initial differences in DW that exist among sibling neonates, so that in some cases the experimental neonates weighed more than their siblings frozen at $t=0$, even though the former were not permitted to feed. At starvation periods approaching 1 day, however, mass changes were easier to measure, and the calculated depletion in lipid mass accounted for 0.43 and 0.57 of the measured change in DW between control (CTL) and experimental (EXP) animals.

We consequently adopted a complementary approach, and a starvation period of about 1 day, to solve the problem through analysis of respiratory $R Q$ and tissue stoichiometry. Neonates from Lake Huron were held at $21.1^{\circ} \mathrm{C}$ (epilimnion collection temperature on 28 August 1995) for intervals from 21 to $28 \mathrm{~h}$ (Table 4), and mean DW at the end of the incubation was compared with neonatal clone-mates that had been frozen at birth. The CHN contents of the neonates initially and at the end of the starvation interval were determined from pooled samples (Table 4).

Because the starvation experiments were similar to the respiration experiments of Lehman \& Branstrator (1995) and the P-excretion experiments of Burkhardt
\& Lehman (1994), the results can be evaluated in parallel. Specifically, respiration losses as oxygen $\left(R, \mu \mathrm{g} \mathrm{O}_{2} \mathrm{~h}^{-1}\right)$ are functions of body mass and temperature:

$R=a W^{b} \times \mathrm{e}^{k T}$

where $a=0.031, b=0.666$ and $k=0.034$. Although eqn 13 is in units of oxygen, carbon equivalents can be calculated from atomic weight ratios and RQ:

$d \mathrm{C} / d t=-R \times(12 / 32) \times R Q$

where the value of $R Q$ depends on the proportions of lipids, proteins, and carbohydrates that are catabolized. For our experimental data, we must further consider the ratio of dry mass to $\mathrm{C}$ content (DW/C $=$ $\gamma$ ). The empirical values for $\gamma$ in the experiment range from 2.02 to 2.11 by mass and average 2.07. Thus, $R Q$ is found by integration of the differential equation:

$d W / d t=-R \times(12 / 32) \times R Q \times \gamma$

where $R$ is a function of $W$ (eqn 13). This equation can be solved as

$W_{\mathrm{f}}=\left[W_{0}^{0.334}-0.0165 \times \Delta t \times R Q\right]^{2.994}$

where $W_{0}$ and $W_{\mathrm{f}}$ represent animals at the beginning and end of the incubation interval, respectively. Statistical estimation of $R Q$ in this equation from the data in Table 4 (nonlinear regression, SYSTAT 5.0) yields $R Q=0.694(\mathrm{SE}=0.046)$. The estimate is very close to the $R Q$ value expected for metabolism of lipids (0.71), but not significantly different at the $95 \%$ confidence level from the expected $R Q$ for metabolism of proteins (0.79). The empirical estimate is clearly different, however, from the value expected for metabolism of carbohydrate (1.0), and suggests that both lipids and proteins may be respired.

Another way to identify substrates used in metabolism is by analysis of the changes in elemental composition. The amount of protein consumed in respiration is calculated by convention as $6.25 \times \Delta N$ (Table 4). Residual mass loss is putatively lipid. The calculated proportions of protein and lipid used in metabolism average $57 \%$ and $43 \%$, respectively (Table 4 ), which is consistent with our independent assessment of lipid content changes.

Our data imply that non-feeding Bythotrephes neonates respire lipids and proteins in similar proportions. The stoichiometry of $\Delta \mathrm{C}: \Delta \mathrm{H}$ (Table 4 ) is consistent with metabolism of compounds less saturated than

(C) 1997 Blackwell Science Ltd, Freshwater Biology, 38, 343-352 
Table 4 Mean DW $(\mu \mathrm{g})$ of neonates in starvation experiment, 28-29 August 1995, Lake Huron, $21.1^{\circ} \mathrm{C}$. Pooled analyses of CHN content $($ precision $=0.1 \%$ ). Protein calculated as $6.25 \times \Delta \mathrm{N}$

\begin{tabular}{|c|c|c|c|c|c|c|}
\hline$W_{0}(\mu \mathrm{g}) \mathrm{CTL}$ & $W_{\mathrm{f}}(\mu \mathrm{g})$ EXP & $\Delta t(\mathrm{~h})$ & $\Delta \mathrm{C}: \Delta \mathrm{N}$ (mass) & $\Delta \mathrm{C}: \Delta \mathrm{N}(\mathrm{mol})$ & $\Delta \mathrm{C}: \Delta \mathrm{H}(\mathrm{mol})$ & $\%$ Protein \\
\hline 51.6 & 42.1 & 21 & 6.53 & 7.62 & 0.58 & 56.9 \\
\hline 86.7 & 70.1 & 23 & 6.40 & 7.46 & 0.58 & 57.6 \\
\hline 40.2 & 29.55 & 24 & 5.55 & 6.47 & 0.58 & 62.8 \\
\hline 95.3 & 83.9 & 24 & 8.88 & 10.36 & 0.56 & 46.5 \\
\hline 82.0 & 69.1 & 24 & 7.18 & 8.37 & 0.57 & 53.6 \\
\hline 74.1 & 61.5 & 24 & 6.84 & 7.97 & 0.57 & 55.3 \\
\hline 77.9 & 68.3 & 24 & 8.64 & 10.08 & 0.57 & 47.3 \\
\hline 73.55 & 60.25 & 24 & 6.60 & 7.70 & 0.58 & 56.5 \\
\hline 43.2 & 33.3 & 24 & 5.88 & 6.86 & 0.58 & 60.7 \\
\hline 66.25 & 51.15 & 24 & 5.89 & 6.87 & 0.58 & 60.6 \\
\hline 57.9 & 45.25 & 24 & 6.00 & 7.00 & 0.58 & 59.9 \\
\hline 62.0 & 44.75 & 24 & 5.45 & 6.36 & 0.58 & 63.4 \\
\hline 59.5 & 44.55 & 24 & 5.66 & 6.60 & 0.58 & 62.1 \\
\hline 36.85 & 30.13 & 28 & 6.57 & 7.66 & 0.58 & 56.7 \\
\hline$\% C=49.5$ & 47.3 & Mean $=$ & 6.58 & 7.67 & 0.58 & 57.2 \\
\hline$\% \mathrm{~N}=11.6$ & 12.2 & $\mathrm{SD}=$ & 1.06 & 1.23 & 0.006 & 5.2 \\
\hline$\% \mathrm{H}=6.9$ & 6.5 & $\mathrm{SE}=$ & 0.28 & 0.33 & 0.002 & 1.4 \\
\hline
\end{tabular}

most lipids on average, and supports our indications that lipids are consumed in combination with proteins. Lipids and carbohydrates contain about the same proportions of hydrogen ( $\mathrm{H}: \mathrm{C}=2$ by moles), and proteins have lower ratios. The observed $\mathrm{H}: \mathrm{C}$ metabolic stoichiometry in Table 4 is about 1.7 by moles, significantly less than 2 .

Growth, metabolism, and tissue stoichiometry by mass balance

Lehman \& Branstrator (1995) showed how to use stoichiometries of metabolism and growth for $\mathrm{C}$ and $\mathrm{P}$ to infer the diet composition of the predator. Following their approach, it is now possible to incorporate $\mathrm{N}$ content. $\mathrm{C}: \mathrm{N}$ by mass ranges only between 4.16 and 4.52 (mean $=4.33)$ without systematic variation with age. Over the ontogeny from neonate to adult the net accounting of prey stoichiometry is given by the sum of accumulated predator tissue and metabolic losses. Most accumulated tissue mass is reproductive material, specifically production of parthenogenic offspring (Table 3). The metabolic losses vary with body mass, but occur at close to fixed ratios (by mass) of $\mathrm{C}: \mathrm{N}=7 \quad$ (Table 4) and $\mathrm{C}: \mathrm{P}=20 \quad$ (Lehman \& Branstrator, 1995).

The basic concept of conservation of mass was used to estimate the stoichiometries of prey consumption. Mass balance dictates that

(C) 1997 Blackwell Science Ltd, Freshwater Biology, 38, 343-352
Consumed mass $=$ accrued mass + released mass $\quad(17)$

for each element. In each case, accrued mass is known empirically, and released $\mathrm{C}: \mathrm{N}: \mathrm{P}$ is also known. Thus, three linear equations in three unknowns can be solved for the consumed stoichiometry of prey $\mathrm{C}: \mathrm{N}: \mathrm{P}$. Calculation works as follows over the interval from birth to first reproduction:

$$
\begin{aligned}
& \text { assimilated-C }=\Delta \mathrm{C}+\text { respired-C } \\
& \text { assimilated- } \mathrm{N}=\Delta \mathrm{N}+\text { excreted-N } \\
& \text { assimilated-P }=\Delta \mathrm{P}+\text { excreted-P }
\end{aligned}
$$

where $\Delta \mathrm{C}$ is the accrual of carbon mass from neonate to primiparous adult:

$\Delta \mathrm{C}=\Delta W \times(\mathrm{C} / \mathrm{DW})$

where $\mathrm{C} / \mathrm{DW}=0.47$ on average in our experience, and accrual of $\mathrm{N}$ and $\mathrm{P}$ are given by

$\Delta \mathrm{N}=\Delta \mathrm{C} /(\mathrm{C} / \mathrm{N})_{\text {mean }}$

$\Delta \mathrm{P}=c\left(W_{F}^{d}-W_{0}^{d}\right)$

where $c=0.047$ and $d=0.741$ (Burkhardt \& Lehman, 1994).

Exuvia molted during shipboard experiments on Lake Michigan were collected during July 1992 to assess the potential contributions to mass budgets. Molts collected from animals at the end of their first instar weighed $4.7 \mu \mathrm{g}(\mathrm{SD}=0.8, n=9$ pooled 
samples), and molts at the end of the third instar weighed $6.8 \mu \mathrm{g}$ ( $\mathrm{SD}=1.3, n=4$ pooled samples). These weights proved negligible compared to other terms, and although they were recorded, they are ignored in the following calculations for simplicity, with no substantial resulting error.

Lifetime respiration is calculated from the respiration rate function (eqn 13) and the growth rate function (eqn 12). Integration over the time interval 0 to $\Sigma D$ yields a function dependent on $W_{0}, g$ and $T$ (note that $\Sigma D$ is an explicit function of temperature).

Respired-C $(\mu \mathrm{g})=0.0121 \times \mathrm{e}^{k T} \times W_{0} / g\left[\mathrm{e}^{b g \Sigma D}-1\right]$

The results (Table 4 and Lehman \& Branstrator, 1995) demonstrate that released $\mathrm{N}$ and $\mathrm{P}$ can be predicted by stoichiometric ratio to Respired-C:

excreted-N $(\mu \mathrm{g})=7 \times$ respired-C

excreted-P $(\mu g)=20 \times$ respired-C.

We now have predictive equations for mass balance that are dependent on a very small number of empirical measurements: temperature, neonate mass and mass of adult females.

Mass balance was calculated by eqns 18-20 for ranges of variables as follows: $T=14-22{ }^{\circ} \mathrm{C} ; W_{0}=25-$ $100 \mu \mathrm{g}$; relative mass gain $=6-10$. The resulting ranges for predicted prey stoichiometries by mass were rather narrow: $\mathrm{C}: \mathrm{N}=6 \quad(\mathrm{CV}=2.5 \%) ; \mathrm{C}: \mathrm{P}=24 \quad(\mathrm{CV}=$ $4.3 \%) ; \mathrm{N}: \mathrm{P}=4(\mathrm{CV}=6.8 \%)$.

\section{Discussion}

The parameters and model equations for secondary production studies with Bythotrephes are listed in Table 5. In Table 6 we present an example calculation of secondary production with field data from Lake Michigan, to illustrate the use of the model equations. The relative rate of individual somatic growth (growth rate to biomass ratio) varies linearly with development rate, $1 / \Sigma D$; for the example illustrated, the ratio of growth rate to biomass is $0.25 \mathrm{day}^{-1}$. Owing to respiratory losses, ingestion efficiencies and assimilation efficiencies, the rate of predation is about three times larger than growth rate, and varies with instar. At typical environmental temperatures, Bythotrephes kills about three-quarters of its body weight in prey each day.

This communication includes several notable
Table 5 Parameters and model equations for secondary production calculations using growth model 3

\begin{tabular}{lll}
\hline Parameters & \\
\hline $\begin{array}{l}\text { Respiration } \\
\alpha=0.031\end{array}$ & $\begin{array}{l}\text { Ingestion efficiency } \\
\text { IE }=0.58\end{array}$ \\
$\beta=0.666$ & Assimilation efficiency $(A E)$ \\
$\mathrm{K}=0.034$ & $\mathrm{AE}=0.85$ & \\
$\mathrm{RQ}=0.7$ & & \\
Development & Stage & Relative age (relage) \\
$a=0.101$ & 1-barb & 0.160 \\
$b=-5.547$ & 2-barb & 0.467 \\
$\Sigma F=6.705$ & 3-barb & 0.807 \\
\hline
\end{tabular}

Model equations

\begin{tabular}{|c|c|}
\hline$D_{\mathrm{e}}$ (days) $=$ & $1 /[24 \exp (a T+b)]$ \\
\hline$\Sigma D$ (days) $=$ & $\Sigma F \cdot D_{\mathrm{e}}$ \\
\hline age (days) $=$ & relage $\cdot \Sigma D$ \\
\hline $\mathrm{DW}(\mu \mathrm{g})=$ & $W_{0} \cdot\left[W_{\mathrm{BE}} / W_{0}\right]^{(\text {relage } / 0.95)}$ \\
\hline$C(\mu g)=$ & $0.47 \cdot \mathrm{DW}$ \\
\hline$d \mathrm{DW} / d t\left(\mu \mathrm{g} \mathrm{day}^{-1}\right)=$ & $\mathrm{DW} \cdot \ln \left[W_{\mathrm{BE}} / W_{0}\right] / 0.95 \Sigma D$ \\
\hline$d \mathrm{C} / d t\left(\mu \mathrm{g} \mathrm{C} \mathrm{day}^{-1}\right)=$ & $0.47 \cdot d \mathrm{DW} / d t$ \\
\hline$R\left(\mu \mathrm{g} \mathrm{C}\right.$ day $\left.^{-1}\right)=$ & $\alpha \mathrm{DW}^{\beta} \exp (K \cdot T) \cdot 12 / 32 \cdot \mathrm{RQ} \cdot 24$ \\
\hline$I\left(\mu \mathrm{g} \mathrm{C} \mathrm{day}{ }^{-1}\right)=$ & $(d \mathrm{C} / d t+R) / \mathrm{AE}$ \\
\hline$P\left(\mu g \mathrm{C} \mathrm{d}^{-1}\right)=$ & $I / \mathrm{IE}$ \\
\hline BIOMASS & $f_{\mathrm{i}} \cdot \mathrm{N} \cdot \mathrm{C}\left(\mu \mathrm{g} \mathrm{C} \mathrm{\textrm {m } ^ { - 2 } )}\right.$ \\
\hline GROWTH = & $f_{\mathrm{i}} \cdot \mathrm{N} \cdot d \mathrm{C} / d \mathrm{t}\left(\mu \mathrm{g} \mathrm{C} \mathrm{m}{ }^{-2} \mathrm{day}^{-1}\right)$ \\
\hline ASSIM = & 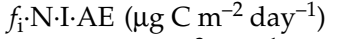 \\
\hline PRED = & 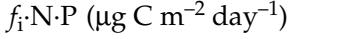 \\
\hline
\end{tabular}

improvements of physiological parameters from previous reports. First, we provide an empirical estimate for $R Q$, based on changes in body mass during starvation. Second, we have revised our old estimate of $\mathrm{C} / \mathrm{DW}=$ 0.52 (Lehman \& Caceres, 1993) downward to 0.47. Both sets of analyses were conducted at the University of Michigan Department of Chemistry CHN/AA analytical laboratory, using the same instrument, but by different analysts. Both numbers were based on large sets of replicates that were internally consistent. However, the present analyst has informed us that earlier standards from 1989 and 1990 may have been in error. We confirmed the new values $(\mathrm{C} / \mathrm{DW}=0.47)$ against independent standards, and find them accurate. Finally, we have expanded the empirical database for development and growth rates, and have selected an empirical model that seems to work across a broader range of temperatures than alternative models. Each of these advances should improve the accuracy of model predictions.

There is always a practical difficulty in discriminat-

(C) 1997 Blackwell Science Ltd, Freshwater Biology, 38, 343-352 
Table 6 Example data and worksheet for secondary production calculations using growth model 3

Data (Lake Michigan example)

\begin{tabular}{lll} 
Temperature & Population demography \\
$T=20{ }^{\circ} \mathrm{C}$ & Stage & frequency $\left(f_{\mathrm{i}}\right)$ \\
Neonate mass & 1-barb & 0.500 \\
$W_{0}=76.5 \mu \mathrm{g}$ & 2-barb & 0.125 \\
$3 \mathrm{BE}$ Mass & 3-barb & 0.375 \\
$W_{\mathrm{BE}}=745.4 \mu \mathrm{g}$ & Abundance: & $n=25 \mathrm{~m}^{-2}$ \\
\hline
\end{tabular}

Example calculations

Individual level

\begin{tabular}{lccclc}
\hline Stage & relage & age (days) & DW & $d \mathrm{DW} / d t$ & $d \mathrm{C} / d t$ \\
\hline Neo & 0 & 0 & 76 & 19.3 & 9.1 \\
1-barb & 0.160 & 1.52 & 112 & 28.3 & 13.3 \\
2-barb & 0.467 & 4.44 & 234 & 59.1 & 27.8 \\
3-barb & 0.807 & 7.68 & 530 & 133.7 & 62.8 \\
& $R$ & $I$ & $P$ & & \\
Neo & 6.9 & 18.8 & 32.4 & & \\
1-barb & 8.9 & 26.2 & 45.1 & & \\
2-barb & 14.6 & 49.8 & 85.9 & & \\
3-barb & 25.1 & 103.5 & 178.4 & & \\
\hline
\end{tabular}

Population level

\begin{tabular}{llcccc}
\hline Stage & $f_{\mathrm{i}}$ & BIOMASS & GROWTH & ASSIM & PRED \\
\hline 1-barb & 0.500 & 659 & 166 & 278 & 564 \\
2-barb & 0.125 & 344 & 87 & 132 & 268 \\
3-barb & 0.375 & 2336 & 589 & 825 & 1673 \\
Total & 1.000 & 3339 & 842 & 1235 & 2505 \\
\hline
\end{tabular}

ing among alternative models when their numerical predictions are very close together. That is the situation in trying to choose between models 1, 2 and 3. The three models diverge only at low temperature; at the normal environmental temperatures at which populations develop, the models are equally good abstractions of the data.

Additional improvements in predictive power of these models will come with the accumulation of additional data for development rates of various instars. We urge that care be taken to record the actual experimental temperatures with both accuracy and precision, because temperature variations can contribute importantly to model formulation error. Bythotrephes presents many features that make it an ideal model organism for population and production studies. Efforts to improve the data base will thus be rewarded by increased predictive ability.

The stoichiometries of metabolism we measured apply to field-collected animals that were immediately incubated at or near acclimation temperatures, but under non-feeding conditions. The incubation intervals were the shortest periods over which we could measure changes with statistical precision, but there is no way to tell from the data if feeding animals would exhibit somewhat different stoichiometries. Because the animals are predators that feed episodically, however, the metabolic rates measured and reported here plausibly correspond to natural rates for animals that are between feeding bouts, or are searching for prey, which may be the majority of their time.

Refinements in parameter values and expansion of the calibration data have not changed the principal conclusions about diet composition that were made by Lehman \& Branstrator (1995). Bythotrephes metabolism and tissue growth reveal its requirement for a diet with very low $\mathrm{C}: \mathrm{P}$ ratio, consistent with use of Daphnia as a primary forage item. Because body carbon loss during starvation is consistent with predictions of our respiration model, there do not appear to be significant residual metabolic loss terms for $\mathrm{C}$ that we have not measured. Bythotrephes is a voracious predator that invests heavily in reproduction and minimizes post-embryonic somatic growth. It seems to nourish itself principally on lipids and proteins, which can readily be obtained from its cladoceran prey. Short maturation times and large reproductive output combine for very rapid growth under favourable environmental conditions, making Bythotrephes a potent, opportunistic predator in plankton communities.

\section{Acknowledgements}

The experimental work was supported in part by grants from the U.S. National Science Foundation. We thank R. Foy, B. Betz, and the captain and crew of the $R / V$ Laurentian for sampling assistance in the field, and we thank D.K. Branstrator for helping to make some of the development rate measurements in 1993 and 1996. CHN analyses were performed by C. Carter, University of Michigan Department of Chemistry. 


\section{References}

Berg D.J. \& Garton D.W. (1988) Seasonal Abundance of the exotic predatory cladoceran Bythotrephes cederstroemi, in Western Lake Erie. Journal of Great Lakes Research, 14, 479-488.

Berg D.J. \& Garton D.W. (1994) Genetic differentiation in North American and European populations of the cladoceran Bythotrephes. Limnology and Oceanography, 39, 1503-1516.

Bilkovic D.M. \& Lehman J.T. (1997) Lipid concentration and size variation of Bythotrephes (Cladocera: Cercopagidae) from Lakes Erie, Huron, and Michigan. Journal of Great Lakes Research, 23, 149-159.

Branstrator D.K. (1994) Profitability of cladoceran prey for Leptodora kindtii. Verhandlungen der Internationale Vereinigung Limnologie, 25, 2413-2417.

Bur M.T. \& Klarer D.M. (1991) Prey selection for the exotic cladoceran Bythotrephes cederstroemi by selected Lake Erie fishes. Journal of Great Lakes Research, 17, 85-93.

Burkhardt S. (1994) Seasonal size variation in the predatory cladoceran Bythotrephes cederstroemii in Lake Michigan. Freshwater Biology, 31, 97-108.

Burkhardt S. \& Lehman J.T. (1994) Prey consumption and predatory effects of an invertebrate predator (Bythotrephes: Cladocera, Cercopagidae) based on phosphorus budgets. Limnology and Oceanography, 39, 1007-1019.

Cullis K.I. \& Johnson G.E. (1988) First evidence of the cladoceran Bythotrephes cederstroemi Schoedler in Lake Superior. Journal of Great Lakes Research, 14, 524-525.

Garton D.W., Berg D.J. \& Fletcher R.J. (1990) Thermal tolerances of the predatory cladocerans Bythotrephes cederstroemi and Leptodora kindti: relationship to seasonal abundance in western Lake Erie. Canadian Journal of Fisheries and Aquatic Science, 47, 731-738.

Lehman J.T. (1987) Palearctic predator invades North American Great Lakes. Oecologia (Berlin), 74, 478-480.

Lehman J.T. (1988) Algal biomass unaltered by food-web changes in Lake Michigan. Nature, 352, 537-538.

Lehman J.T. (1991) Causes and consequences of cladoceran dynamics in Lake Michigan: implications of species invasion by Bythotrephes. Journal of Great Lakes Research, 17, 437-445.

Lehman J.T. (1993) Efficiencies of ingestion and assimilation by an invertebrate predator using $\mathrm{C}$ and $\mathrm{P}$ dual isotope labeling. Limnology and Oceanography, 38, 1550-1554.

Lehman J.T. \& Branstrator D.K. (1995) A model for growth, development, and diet selection by the invertebrate predator Bythotrephes cederstroemi. Journal of Great Lakes Research, 21, 610-619.

Lehman J.T. \& Branstrator D.K. (1996) Predicting assimilation and development rates of invertebrate predators. Journal of Great Lakes Research, 22, 930-934.

Lehman J.T. \& Caceres C.E. (1993) Food-web responses to species invasion by a predatory invertebrate: Bythotrephes in Lake Michigan. Limnology and Oceanography, 38, 879-891.

Lehman J.T. \& Lehman D.A. (1996) Status of the nonindigenous invertebrate predator Bythotrephes (Crustacea: Cladocera) in Lakes Erie, Huron, and Michigan. Proceedings of Symposium on Non-Indigenous Species in Western Aquatic Ecosystems. Portland State University of Lakes and Reservoirs Prog. Publ. no. 968, 7-14.

Sprules W.G., Riessen H.P. \& Jin E.H. (1990) Dynamics of the Bythotrephes invasion of the St. Lawrence Great Lakes. Journal of Great Lakes Research, 16, 346-351.

Vanderploeg H.A., Liebig J.R. \& Omair M. (1993) Bythotrephes predation on Great Lakes' zooplankton measured by an in situ method: Implications for zooplankton community structure. Archiv fuer Hydrobiologie, 127, 1-8.

Yan N.D. \& Pawson T.W. (1997) Changes in the crustacean zooplankton community of Harp Lake, Canada, following the invasion by Bythotrephes cederstroemi. Freshwater Biology, 37, 409-425.

Yurista P. (1992) Embryonic and post-embryonic development in Bythotrephes cederstroemi. Canadian Journal of Fisheries and Aquatic Science, 49, 1118-1125.

(Manuscript accepted 16 June 1997) 